\title{
Accounting
}

\section{Determinants influencing cost system in Vietnam's public hospitals}

\author{
Hoang Van Tuonga, Lai Thi Thu Thuy ${ }^{b^{*}}$ and Dinh Hoai Nam
}

\author{
${ }^{a}$ Academy of Finance, Vietnam \\ ${ }^{b}$ Thuongmai University, Vietnam \\ ${ }^{c}$ Institute of Technology Development, Vietnam \\ Article history: \\ Received March 102020 \\ Received in revised format March \\ 152020 \\ Accepted June 102020 \\ Available online \\ June 122020 \\ Keywords: \\ Cost system \\ Public hospital \\ Vietnam
}

\section{A B S T R A C T}

\begin{abstract}
In Vietnam, public hospitals are increasingly operating in a highly competitively environment and therefore cost management has become an imperative. The purpose of this research is to establish the factors influencing cost system development success among public hospitals in Vietnam. In order to achieve this objective, some primary and secondary data were used. The secondary data include books, journals, periodicals, unpublished research materials and the internet and the primary data include interview and a well-structured questionnaire administered to 260 respondents in the 50 public hospitals sampled from the population. The data collected from the questionnaire were analyzed using relevant econometric tests. The results suggest a relationship between the factors influencing the cost system development in public hospitals in Vietnam.
\end{abstract}

\section{Introduction}

The health sector is one of the most important parts of the service sector due to its impact on the protection as well as promotion of human life. Hospital organizations have been facing difficulties and challenges in balancing limited resources and costs to provide their demand for services. Historically, hospitals have worked for decades under unconcerned managers regarding services costs management. Moreover, up to current days, attempts for measurements and control have not been well accepted. One of the main challenges of hospital managers is development of cost information for decision-making and proper pricing of services. Hospital managers must provide health-care services needed by the community at an acceptable level of quality and at the least possible cost; therefore, they need information on the actual cost of the services they provide. The basic purpose of cost systems is to determine the cost of a product or service by assigning manufacturing costs to products or services that company produces or provides. cost system consist of different accounting methods used in order to define the cost per unit. Accounting methods used in cost system enable the evaluation of products as a result from the manufacturing or providing process. It is important to point out that different cost systems differently affect the product or service evaluation. The choice of cost system was based on the type of the production process. Today, traditional cost systems which are no longer suitable to use in modern operating conditions. Business conditions are changing rapidly becoming more and more complex. The most

* Corresponding author. Tel.: 84.904685411

E-mail address: laithuy@tmu.edu.vn (L. T. T. Thuy) 
important direct cost element in modern cost structure becomes indirect costs (overheads). This change in cost structure found traditional cost systems inappropriate for product or service evaluation. In order to avoid the inaccuracy of traditional cost systems in product or service evaluation, the new cost systems such as based on activities, time- driven activities, performancefocused activities and ratio of cost to charges have been developed. Modern costing methods are very popular in many developed countries and more familiar with many developing counties such as China, Thailand, Malaysia, etc. However, it is still a new method in Vietnam. There were very few studies related to these issued in Vietnam.

In this study, we examined factors influencing the by using a survey data. The factors we examined cost variability, cost important, perceived complexity, organizational support, system state, satisfaction legal system, use legal system. We tested our model and hypotheses by using a sample of 260 respondents in the 50 public hospitals in Vietnam.

The remainder of the paper is organized as follows. First, we discussed the theoretical background of our study focusing on cost accounting methods, field study and offer our research hypotheses. Second, we described the research method approach. Third, we present our results that test our predictions. Finally, we offer a discussion of the research results before concluding.

\section{Literature review}

\subsection{Cost Accounting Methods}

Cost accounting is the process of estimating and classifying costs incurred by an organization. These costs can be analyzed at the organizational or departmental level, but Gapenski and Reiter have noted that "the holy grail of cost estimation is costing at the service or individual patient level" (2016). It seems Gapenski acknowledged the increasinglyimportant role cost accounting is likely to play in the health-care market. The most recent updates of his widely-used textbooks on health care finance and accounting included much-expanded coverage of techniques for estimating costs at the product or service level. As different industries have evolved over time so have cost accounting methods and the management accounting research analyzing these methods (Kaplan and Porter, 2011). Different approaches to managerial and cost accounting have emphasized different components of the methodologies such as, accurate cost capture or the ability to capture financial and non- financial performance measures (Ittner, Larcker and Meyer, 2003). There is a wide spectrum of costing methodologies (e.g. value-based management, benchmarking, life cycle costing, and target costing) that can help inform managers. The literature has identified various cost management accounting techniques, such as, activity-based costing (ABC), activity-based management (ABM), time-driven ABC, target costing, balanced scorecards (BSC) and ratio of cost-to-charges (RCC) (Kaplan \& Anderson, 2007; Amiri \& Khmidi, 2019). This paper will focus on five specific cost accounting techniques seen primarily in the health-care environment: traditional costing, activity-based costing, time-driven activity based costing, performance-focused activity based costing.

Traditional Costing is a cost accounting methodology that allocates organizational overhead to a specific output based on a predetermined cost driver or by using a pre-determined percentage rate (Paulus, van Raak and Keijzer, 2002). The traditional costing technique is easy to understand and apply. It requires minimal financial and/or managerial investment which helps explain its wide use and acceptance. However, these costing methods have been criticized for failing to account for differences in product/service lines and marketing channels and for producing inaccurate and unrealistic representations of a product or service's true cost.

Activity-Based Costing is a costing approach developed by Kaplan in the mid-1980s. Activity- based costing (ABC) has been the subject of numerous articles and books (Cooper \& Kaplan, 1991; Gapenski \& Reiter, 2016; Kaplan \& Cooper, 1998). This approach has been widely adopted in public and private, service and managerial organizations. Activity based costing is widely used in the preparation of budgets as it serves as a planning mechanism that shows the relationship between goal achievement and resource intensity. Activity based costing takes a rational approach to product and service costing, since it begins with an effort to identify the fundamental activities and resources involved in producing an output. The indirect expenses are then allocated to the activities using cost drivers that are carefully selected to reflect the use of each particular resource pool. This methodology has been found to produce accurate and rational financial management information, and to provide information that helps managers make accurate product mix decisions, product price calculations, and consumer profitability analyses (Horngren et al., 2010).

The basis for $\mathrm{ABC}$ is a belief that all activities exist to support the production and delivery of goods and services and that all indirect costs can be traced and allocated to individual products and services (Velmurugan, 2010). Activity based costing provides managers a more accurate view of the 'true' cost of their products and services. The accuracy of the ABC can lead to different evaluations of costs and profitability as compared to other simpler costing approaches. Activity based costing is designed to provide more accurate information about product costs so that management can focus its attention on value-added activities (Velmurugan, 2010). Activity based costing has been found to generate information that is superior to traditional systems (McGowan, 1998). The use of ABC systems has been found to help organizations make better product mix decisions, product price calculations, and consumer profitability analyses. The use of ABC is also associated with improved firm performance and increased manager and employee satisfaction. 
Time-Driven Activity Based Costing (TDABC) is a managerial accounting approach introduced in 2004 by Kaplan and Anderson. Time-driven activity-based costing is an attempt to overcome some of the weaknesses associated with ABC. TDABC differs from traditional $\mathrm{ABC}$, in that time is used as the primary cost driver. The assumption underlying the TDABC method is that most resources (i.e. manpower, equipment, and facilities) have capacities that can be measured in terms of time (Namazi, 2009). TDABC does not require the identification of 'activities' that the ABC method does. With TDABC no individual activities are needed because the default cost driver is time. TDABC reduces the influence of personal preferences on cost estimation by eliminating managerial discretion in cost driver selection.

Time-driven activity-based costing is simpler to implement than $\mathrm{ABC}$ and it integrates well with available data from electronic resource planning systems. Time-driven $\mathrm{ABC}$ also enables fast and inexpensive cost model maintenance (Kaplan and Anderson, 2004, 2007). However, the features that make TDABC easier to implement can reduce its usefulness relative to ABC. Under the TDABC system, the activities associated with the indirect expenses are not identified. Time-driven $A B C$ uses a single activity measure and this single cost-time relationship may not represent the actual cause-effect behavior of the costs (Namazi, 2009). The identification of specific drivers can potentially help identify inefficient processes which is one of the most valued components of ABC. Using time as a measure for practical resources may be relevant for some small service firms but not suitable for other more complex enterprises with different department outputs since indirect costs cannot be tied back to the employees' work time (Namazi, 2009). This may hold especially true in a health-care organization where different activities may require a wide range of skill sets.

Performance-Focused Activity Based Costing (PFABC) is a third iteration of $\mathrm{ABC}$. PFABC is a hybrid $\mathrm{ABC}$ method that attempts to overcome some of the weaknesses associated with TDABC and ABC. PFABC attempts to extend the value of this managerial cost system as a means to examine organizational performance. PFABC is an intensive costing process that requires several steps to properly allocate indirect expenses. $\mathrm{PFABC}$ is similar to $\mathrm{ABC}$ in that it requires the identification of major cost activities but dissimilar to TDABC in the ways that activities' resource use is determined. With PFABC, the actual resources for each activity can be assessed in a variety of ways, including interviews, surveys, or based on actual utilization of time, materials or other resources (Namazi, 2009). This is a difference between PFABC and conventional ABC, where the cost driver is determined via specific activities or TDABC where the cost driver is time.

The other significant difference between PFABC and other costing approaches is that PFABC calculates the cost drivers' standard rate (quantity) and price variances. This helps managers evaluate the true drivers of cost by separating the analysis of volume and price variances. The extra processes in the PFABC approach make PFABC more difficult to establish but enable $\mathrm{PFABC}$ to offer a richer and more detailed examination of the organization's activities.

PFABC does hold several advantages over the traditional ABC and TDABC (Namazi, 2009). PFABC focuses more on the implementation stage by identifying each important activity explicitly and directly mapping the resource costs to the activities. PFABC's focus on budget variances also helps managers to identify excess capacity. PFABC offers managers more information than other accounting methods. It is a powerful planning and performance evaluation tool, as it can identify variances, such as rate, efficiency, and volume variances. It is the one costing mechanism that is used to examine the efficiency and effectiveness of an organization.

\subsection{Field Study: The Public Hospitals in Vietnam}

Over the past decades, the health care activities in Vietnam have been strongly promoted to meet increasing demand of the people. Therefore, the systematic development of hospitals and medical centers has also been encouraged. Recently, the health care system has come to be mixed between public and non-public health care providers. The public ones are still playing dominant roles, especially in prevention, research, and training. There are three levels of hospitals and medical centers: central level, provincial level, and district level.

Although many public hospitals have successfully transferred from fully state-subsidized mechanism into self-independent financial model, there remain difficulties for both hospitals and patients after the change. These problems include hospitals facing higher costs for upgrading technology and equipment while patients spending more on doctor care, which were previously supported by the state budget. The model, while encouraging doctors to improve both their attitude and services, means that the hospitals will have to be responsible for their own loans and monthly interest payment as well as the quality of medical workers. Another issue that could worsen over time is the overlapping in the preventive health-care system and the overload at centrallevel hospitals. Thanks to financial autonomy, more hospitals have invested boldly in high-technology applications, which will take away patients from local-level hospitals and clinics and gradually create a difference within the two-tier health-care system.

Economic growth and demographic changes are driving demand for health-care services throughout Vietnam, and not just in the two economic centers of Hanoi and Ho Chi Minh City. Public, provincial-level hospitals funded by the governments are undergoing upgrades of their facilities and opening new departments for specialty treatment. Such developments are creating new opportunities for medical devices in Vietnam. The country represents a potentially large health-care and medical equipment market. According to Business Monitor International (BMI), Vietnam's health-care expenditure was estimated at \$16.1 billion 
in 2017, which represented 7.5 percent of the country's GDP. BMI forecasts that health-care spending will grow to $\$ 22.7$ billion in 2021, recording a compound annual growth rate (CAGR) of approximately $12.5 \%$ from 2017 to 2021 . In particular, Vietnam's public health-care expenditure is predicted to increase at a CAGR 9.5\% in the period of 2016-2021 compared with 17.2\% in the period of 2011-2016. This is partly due to the government's effort in promoting partnerships between public and private health-care providers to share the cost. Private health-care expenditure is expected to grow at a CAGR of $7.5 \%$, with a large part of the growth due to increased insurance coverage for employees. The Vietnam health-care sector is currently facing the following challenges:

- Most hospitals are outdated and face chronic overcrowding. Hospitals in major cities like Ho Chi Minh and Hanoi often do not have the capacity to serve both local and provincial patients.

- Much of the existing medical equipment in public hospitals in Vietnam is obsolete and needs replacement. Many hospitals lack sufficient equipment for surgery and intensive care units.

V Vietnamese public hospitals rely largely on a State budget to upgrade their facilities, equipment, and services. The total budget for the health sector has increased, but is still too low to meet the demands.

- A shortage of qualified medical staff is common in many hospitals. Doctors and nurses work under stressful conditions and wages are relatively low.

- As high-quality health-care service is not available in country, Ministry of Health (MOH) estimates that around 40,000 Vietnamese people spend approximately $\$ 2$ billion to travel abroad for high quality medical service every year.

\subsection{Hypothesis development}

Drawing from Cardinaels et al.'s (2003) summary and previous research in the area, we examine the importance variables in explaining the decision for public hospitals usage the cost system development. Specifically, we examine: cost variability, cost importance, system state, perceived complexity, organizational support, satisfaction legal system, use legal system.

\section{Cost variability}

Cost variance is the difference between a cost's actual amount and its budgeted or planned amount. Firms with a higher level of indirect overhead and greater heterogeneity in the way products make use of the firm's resources, are expected to introduce more refined cost systems (Bjornenak, 1997; Krumwiede, 1998; Gupta \& King, 1997). This issue may also play a role in a hospital context. Hospitals are often known as settings with many indirect cost categories. They further treat various patients via divergent care processes that often consume overhead differently.

Thus, it can be hypothesized that:

Hypothesis 1 (H1): Cost variability has a positive impact on the extent of cost system development.

\section{Cost importance}

The cost information system plays an important role in every organization within the decision-making process. An important task of management is to ensure the control over operations, processes, activity sectors, and not ultimately on costs. This issue mainly captures the way firms in other industries perceive cost data as crucial for their decisions and their competitive position (Estrin et al., 1998). Given the current pressure on margins, this issue may especially apply to hospitals. We predict that the stronger the importance attached to cost data, the more likely that a hospital will adapt its cost system.

Thus, it can be hypothesized that:

Hypothesis 2 (H2): Cost importance has a positive impact on the extent of cost system development.

\section{System state:}

The system state is a combination of critical system components. This issue concerns the general elaboration of the IT-system within a firm. The more elaborated and integrated the system and the more performance measures it gathers, the easier it is to introduce cost systems that make use of IT-systems and their information (Cooper, 1988). However, given that systems in the health care sector are often designed to only fulfil legal requirements (Jackson, 2001), the culture and the resources within a hospital may not yet be established to integrate different system applications and various types of performance information. Thus, it can be hypothesized that:

Hypothesis 3 (H3): System state has a positive impact on the extent of cost system development.

\section{Perceived complexity:}

Perceived complexity is the degree to which an innovation is difficult to understand and use. This issue in fact captures whether the firm's operational environment is perceived as complex. Arguments in other industries seem to suggest that complex- 
dynamic organizations may especially benefit more from accurate cost systems (Cooper, 1988; Anderson, 1995). This seems true for complex organizations such as hospitals that often treat highly complex care processes. A possible counter argument is that this perceived complexity may obstruct cost system improvement; the cost system problem requires very specific data from these complex processes, which may be too difficult to obtain in hospital settings.

Thus, it can be hypothesized that:

Hypothesis 4 (H4): Perceived complexity has a positive impact on the extent of cost system development.

\section{Organizational support:}

Organizational support is the degree to which employees believe that their organization values their contributions and cares about their well-being and fulfills socioemotional needs. This aspect captures the organizational support towards cost system use. While cost innovations in other industries flow from top management support (Shields, 1995), hospitals are further unique in a sense that they have to work with physicians that are implicitly contracted without being employed for the hospital (Eldenberg, 1994; Elckloo et al., 2004; Le \& Nguyen, 2019; Abdullah \& Senan, 2019). As physicians are responsible for a large part of the health care expenditures, their support towards cost control in general may be important for further cost system enhancement. Besides management and physicians, the support of the heads of various nursing departments is an additional factor that should not be overlooked. In sum, hospitals may be further evolved on the spectrum of cost system design when different organizational members support cost control.

Thus, it can be hypothesized that:

Hypothesis 5 (H5): Organizational support has a positive impact on the extent of cost system development.

\section{Satisfaction legal system:}

As already mentioned, hospitals are legally required to use a predefined cost allocation scheme. This unique setting allows us to test to which extent hospitals are satisfied with this system. Due to the level of detail, satisfaction may be high, such that hospitals may not screen other options of cost system design (Innes and Mitchell, 1999). Conversely, criticisms within a hospital suggesting that the legal system would still produce unreliable cost estimates may however initiate cost system change (Kerschner \& Loper, 1987).

Thus, it can be hypothesised that:

Hypothesis 6 (H6): Satisfaction legal system has a negative impact on the extent of cost system development.

\section{Use legal system:}

This factor can be perceived as slightly different from the previous one. While being unsatisfied about the legal system, hospitals may still consider the system sufficient and consequently use it for their decisions. However, if management starts to question the decision usefulness of these figures (Jackson, 2001), hospitals may be more likely to change towards refined costing such as $\mathrm{ABC}$. Thus, it can be hypothesized that:

Hypothesis 7 (H7): Use legal system has a negative impact on the extent of cost system development.

\section{Research methodology}

\subsection{Data collection}

Researchers usually employ either a qualitative approach or a quantitative approach. The qualitative approach is used to explore factors that are related to the research questions, while the quantitative approach is used to test relationships between these factors. This study is an explanatory study which was based on theory testing. To test the hypotheses in this study, a large amount of cross-sectional data is needed. Therefore, the quantitative approach is more appropriate for this study than the qualitative approach. Data was collected using five main different sources for triangulation: public documentation, interviews, site visits, survey questionnaire survey and assisted access to the organization's information systems. First we analyzed public documentation related to cost systems in health-care sector (annual reports, governmental studies, internet literature) which provided important background information. Second, the visits to the organization provided the main data for the analysis, in particular interviews. The in-depth nature of semi-structured interviews could possibly discover other practical issues not commonly discussed in research articles or textbooks. The semi-structured interviews were conducted with individual staff members; therefore the unit of analysis for this study is individual staff members. The targeted population selected for the semistructured interview comprised 17 staff members who are senior and middle managers and accountants (cost system users) in public hospitals. Furthermore, these interviewees had different roles in cost system development: as part of the project team, as users, or as external observers. Each interview was based on a previously defined check list. Fourth, site visits added further sources of data for the study: the direct observation of plants, laboratories, delivering and stocking areas and access to internal programs and archives. This access was particularly important in understanding the difficulties of the cost system exercise and 
the complexity of the processes tackled. For testing the relationship between the variables and the usage of cost system, data for this study were collected using survey questionnaire. The questions in the survey are taken from previous researchers with some slight modifications. We first developed all scales and questions in English and then translated in to Vietnamese. In order to ensure the purpose of accuracy and correct understanding, two Vietnamese experts in English checked the translations. Most of the questions used five-point Likert scale which is equivalent to " $1=$ strongly disagree", " $2=$ disagree", " $3=$ neutral", " $4=$ agree", and "5 = strongly agree". Sample are selected through purposive sampling technique.

\subsection{Research Model and Data Processing}

Our research model is presented in Figure 1 (see Appendix). Fig. 1 shows the relationship between two parts of the model. The first part is concerned with seven variables. The second part is concerned with the extent of cost system development.

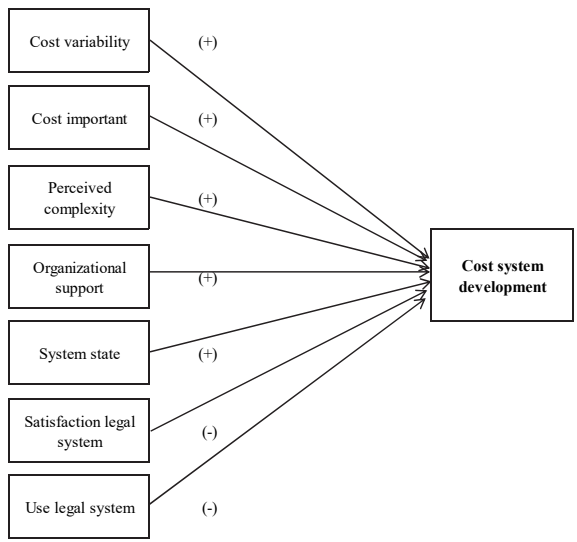

Fig. 1. Research Model

We adopted and modified scale from several previous researchers (See Table 1).

\section{Table 1}

The constructs of the adapted research model with relevant studies

\begin{tabular}{|c|c|}
\hline Coding & Construct Factors/Items \\
\hline & Independent variables \\
\hline $\mathrm{X} 1$ & Cost variability \\
\hline d1 & Certain care processes (DRG's), patients require more costs than others \\
\hline $\mathrm{d} 2$ & The indirect costs constitute a larger part of total costs \\
\hline $\mathrm{X} 2$ & Cost importance \\
\hline d3 & Cost information is important for staying competitive as a hospital \\
\hline $\mathrm{d} 4$ & Accurate cost data is crucial for our hospital \\
\hline $\mathrm{x} 3$ & System state \\
\hline d5 & Cost systems are linked to a spectrum of different performance measures \\
\hline d6 & The various IT systems (electronic patient files, inventory) are strongly integrated \\
\hline d7 & It is difficult to use our systems for defining standard activities at the patient level \\
\hline $\mathrm{X} 4$ & Perceived complexity \\
\hline $\mathrm{d} 8$ & Care process in our hospital are highly complex \\
\hline d9 & For our specific hospital it is complex to allocate cost in an accurate manner \\
\hline $\mathrm{X} 5$ & Organizational support \\
\hline $\mathrm{d} 10$ & The board of directors strongly supports cost allocation (top management) \\
\hline d11 & The medical board strongly supports cost system use (physician) \\
\hline $\mathrm{d} 12$ & The physicians strongly favor the use of cost systems (physician) \\
\hline d13 & Heads of various nursing departments support cost control (nursing) \\
\hline $\mathrm{X} 6$ & Satisfaction legal system \\
\hline d14 & We are satisfied with the legal cost system \\
\hline d15 & Cost drivers of the legal system allocate cost in a logical manner \\
\hline d16 & Cost calculated under the legal system quite accurately reflect the true cost \\
\hline $\mathrm{X} 7$ & Use legal system \\
\hline d17 & The legal system is easy to use \\
\hline d18 & The legal system is not optimal but it satisfies our decision needs \\
\hline d19 & The legal system is often used in our decisions \\
\hline $\mathrm{Y}$ & Dependent variable \\
\hline 0 & Use cost system according to state regulations \\
\hline 1 & Use cost system according to state regulations with modified \\
\hline
\end{tabular}


The data collected for this study were analyzed using a SPSS 20.0 software. The dependent and the independent variables were each assign a code that will aid the interpretation of the output from the SPSS system. In the SPSS software program, coefficient alpha, factor and item-to-totalcorrelation analysis was used to structure and classify the variables. The different questions were asked pertaining to each of the variables was collapsed into a single variable. Then, logistic regression method was used to analyze the data. Test of reliability determines if the variables should be included (or omitted) for further analysis. A specified value of Cronbach's alpha is used as a cut-off point in making the decision. For this study, Cronbach's alpha of 0.7 is applied. Factor analysis was performed on all items that form independent variables of this study. The purpose of this test is to determine the appropriate groupings of these variables for further analysis. For the purpose of this study, the cut-off point for significant loading is $>.400$. This is in line with Hair et al. (1998) who considered items that display factor loading of .400 and above as important. Finally, the logistic regression analysis is used to test the hypothesis. Logistic regression is suitable when the variable under study is categorical.

\section{Results and discussion}

\subsection{Reliability analysis}

The value is defined as Cronbach's coefficient alpha that is between 0 and 1 in most cases. 0 indicates no internal consistency and reliability, while 1 indicates strong internal consistency and reliability (Bryman \& Bell, 2007). A result of less than .400, indicates that the item measures something different from the scale as a whole. From the Cronbach's coefficient alpha result, all values exceed .400 , showing efficient internal reliability for all measurement items in our survey. The main alpha values of independent variables $(\mathrm{X} 2, \mathrm{X} 3, \mathrm{X} 4, \mathrm{X} 5, \mathrm{X} 6, \mathrm{X} 7)$ are all over .700, proving very good internal consistency and reliability for the scales in our survey. The Corrected Item-total Correlation for all items were over .400, indicating acceptable level of reliability. The result of the reliability test is summarized in Table 2 .

\section{Table 2}

The result of the reliability test and factor analysis

\begin{tabular}{|c|c|c|c|c|}
\hline Construct Factors & Items & Cronbach's alpha & Corrected Item-total Correlation & Factor loading \\
\hline \multirow{2}{*}{$\mathrm{X} 1$} & $\mathrm{~d} 1$ & \multirow{2}{*}{.620} & .499 & .796 \\
\hline & $\mathrm{d} 2$ & & .499 & .875 \\
\hline \multirow{2}{*}{$\mathrm{X} 2$} & d3 & \multirow{2}{*}{.821} & .697 & .906 \\
\hline & $\mathrm{d} 4$ & & .697 & .901 \\
\hline \multirow{3}{*}{$\mathrm{X} 3$} & $\mathrm{~d} 5$ & \multirow{3}{*}{.768} & .617 & .823 \\
\hline & d6 & & .688 & .868 \\
\hline & $\mathrm{d} 7$ & & .575 & .796 \\
\hline \multirow{2}{*}{$\mathrm{X} 4$} & $\mathrm{~d} 8$ & \multirow{2}{*}{.857} & .758 & .912 \\
\hline & $\mathrm{d} 9$ & & .758 & .918 \\
\hline \multirow{4}{*}{$\mathrm{X} 5$} & $\mathrm{~d} 10$ & \multirow{4}{*}{.878} & .578 & .731 \\
\hline & d11 & & .836 & .904 \\
\hline & $\mathrm{d} 12$ & & .769 & .850 \\
\hline & $\mathrm{d} 13$ & & .778 & .857 \\
\hline \multirow{3}{*}{ X6 } & d14 & \multirow{3}{*}{.757} & .616 & .810 \\
\hline & $\mathrm{d} 15$ & & .621 & .826 \\
\hline & $\mathrm{d} 16$ & & .554 & .734 \\
\hline \multirow{3}{*}{$\mathrm{X} 7$} & d17 & \multirow{3}{*}{.890} & .719 & .839 \\
\hline & $\mathrm{d} 18$ & & .837 & .935 \\
\hline & $\mathrm{d} 19$ & & .851 & .931 \\
\hline
\end{tabular}

\subsection{Factor analysis}

In factor analysis, all items measuring same construct loaded on a single factor with high factor loading ranging from .600 to .900 which establishes convergent validity or convergence of all items to their respective theoretical defined constructs (Hair et al., 2014). Similarly, not a single case is there where cross factor loading is greater than .500 and all items loaded on their respective factors and it indicates the existence of discriminant validity.

In this study, two factors analyses were conducted using the principal extraction method and varimax rotation of 19 items of the independent variables group. The Kaiser-Meyer-Olkin measure of sampling adequacy was .691. This value was significant. Similarly, Bartlett's test of Sphericity was significant $(\mathrm{p}<.000)$, indicating sufficient correlation between the variables. Hence, $\mathrm{KMO}$ and Bartlett's test proved the suitability of current data for factor analyses. The high values of item-to-total correlation are also supporting the convergence validity and internal consistency of constructs. The factors analysis results are summarized in Table 2 (see Appendix). 


\subsection{Factors influencing the cost system development and hypotheses testing}

In order to examine the relationship between the cost system development and all independent factors, correlation and regression analyses are used. The Table 3 illustrates that cost system development is significantly correlated and has positive relationship with X1 $(\mathrm{r}=.401, \mathrm{p}<.01), \mathrm{X} 2(\mathrm{r}=.459, \mathrm{p}<.01), \mathrm{X} 3(\mathrm{r}=.380, \mathrm{p}<.01), \mathrm{X} 4(\mathrm{r}=.362), \mathrm{X} 5(\mathrm{r}=.716, \mathrm{p}<.01)$. The relationship cost system development is significant and has negative relationship with $\mathrm{X} 6(\mathrm{r}=-.510, \mathrm{p}<.01)$ and $\mathrm{X} 7(\mathrm{r}=.-523, \mathrm{p}<.01)$. The finding suggests that all independent variables have significant influence on cost system development among public hospitals in Vietnam. The value in parentheses denotes the significant value of each variable. Therefore, all hypotheses are supported.

Table 3

Correlation Matrix

\begin{tabular}{|c|c|c|c|c|c|c|c|c|c|c|}
\hline & Variables & $\mathbf{N}$ & 1 & 2 & 3 & 4 & 5 & 6 & 7 & 8 \\
\hline 1 & $\mathrm{X} 1$ & 260 & 1 & & & & & & & \\
\hline 2 & $\mathrm{X} 2$ & 260 & .006 & 1 & & & & & & \\
\hline 3 & $\mathrm{X} 3$ & 260 & .102 & $.507 * *$ & 1 & & & & & \\
\hline 4 & $\mathrm{X} 4$ & 260 & .119 & $.629 * *$ & $.653 * *$ & 1 & & & & \\
\hline 5 & X5 & 260 & $-.211 * *$ & $.489 * *$ & $.403 * *$ & $.304 * *$ & 1 & & & \\
\hline 6 & X6 & 260 & .002 & $.605 * *$ & $.818 * *$ & $.521 * *$ & $.577 * *$ & 1 & & \\
\hline 7 & $\mathrm{X} 7$ & 260 & -.019 & $-.397 * *$ & $-.356 * *$ & $-.336 * *$ & $-.622 * *$ & $.452 * *$ & 1 & \\
\hline 6 & $\mathrm{Y}$ & 260 & $.401 * *$ & $.459 * *$ & $.380 * *$ & $.362 * *$ & $.716 * *$ & $-.510 * *$ & $.523 * *$ & 1 \\
\hline
\end{tabular}

** Correlation is significant at the 0.01 level (2-tailed).

* Correlation is significant at the 0.05 level (2-tailed).

Multicollinearity can cause unstable estimates and inaccurate variances which affects confidence intervals and hypothesis tests. $\mathrm{X} 2, \mathrm{X} 3$ are highly correlated with $\mathrm{X} 1, \mathrm{X} 4, \mathrm{X} 5, \mathrm{X} 6$ and $\mathrm{X} 7$. So that, they were decided to exclude them from the analysis before running logistic regression. Logit (also called logistic regression) estimates models in which the dependent variable is a dichotomous dummy variable - the variable can take only two values, 1 and 0 . These models are typically used to predict whether or not some event will occur. This method uses an estimation technique called Maximum Likelihood Estimation (MLE), an advanced algorithm that calculates the coefficients that would maximize the likelihood of viewing the data distributions as seen in the data set. It is also not subject to the same degree to the classical assumptions that must be met for a reliable linear regression. The logistic regression estimates help to determine the intensity of influencing each factors may offer. The adjusted $\mathrm{R}^{2}$ - Nagelkerke indicates that the regression model explains $84.6 \%$ of the variance in cost system development (see Table 4).

Table 4

Model Summary

\begin{tabular}{cccc}
\hline Step & -2 Log likelihood & Cox \& Snell R Square & Adjusted R Square \\
\hline 1 & $90.665^{\mathrm{b}}$ & .619 & .846 \\
\hline
\end{tabular}

From the Classification Table shown in Table 5 below, it can be said that, the model predicted the value 0 - Use cost system according to state regulations, but the actual value (observed value) was 1- Use cost system according to state regulations with modified. It also shows that if the model were to predict the Y-values as 0 or 1 , the model would be correct $92.7 \%$ times. This is a high percentage compared to the naïve model of $50 \%$.

Table 5

Classification

\begin{tabular}{cccc}
\hline & & & Predicted \\
\cline { 2 - 4 } Observed & & Adopt & Percentage Correct \\
\hline Adopt 0.00 & 0.00 & 1.00 & 84.2 \\
1.00 & 80 & 15 & 97.6 \\
Overall percentage & 4 & & 92.7 \\
\hline * & & &
\end{tabular}

* The cut value is .050.

\subsection{Factors Influencing cost system development}

In order to determine which variable has significant impact on cost system development, Table 6 on Variables in the Equation is referred. From the analysis, it can be seen that five variables are statistically significant (at $p<0.05$ and $p<0.1$ ) in the relationship between the proposed variables and the cost system development. From Table 6 , it can be said that if $p$ value is below 0.1 , the variable is significant at the $90 \%$ level. In this study, all five variables X1, X4, X5, X6, X7 are significant. 
Table 6

Variables in the Equation

\begin{tabular}{|c|c|c|c|c|c|c|c|}
\hline & & B & S.E & Wald & df & Sig. & $\operatorname{Exp}(\mathrm{B})$ \\
\hline \multirow{6}{*}{ Step $1^{\mathrm{e}}$} & $\mathrm{X} 1$ & 7.886 & 1.868 & 17.814 & 1 & .000 & .000 \\
\hline & $\mathrm{X} 4$ & 1.829 & .684 & 7.145 & 1 & .005 & 6.228 \\
\hline & X5 & 2.581 & .838 & 9.488 & 1 & .002 & 13.209 \\
\hline & X6 & -3.099 & 1.097 & 7.976 & 1 & .005 & .045 \\
\hline & X7 & -3.005 & .892 & 11.341 & 1 & .001 & .050 \\
\hline & Constants & 36.577 & 9.849 & 13.792 & 1 & .000 & .000 \\
\hline
\end{tabular}

a. Variable(s) entered on step 1: $X 1, X 4, X 5, X 6, X 7$

Table 6 indicates the degree of relationship of predictors have with cost system development. The factor that had the strongest effect on cost system development was cost variability $(\beta=7.886, p=.000)$, these values support the hypothesis $1(\mathrm{H} 3)$ that cost variability has a positive impact on the extent of cost system development. This positive effects of X1 dimensions are consistent with Krumwiede (1998); Gupta (1997); Eddy et al., empirical findings indicate that increasing levels of cost variability lead to a greater need for cost system development. System state had the second strongest effect $(\beta=2.581, p=.002)$, these values support the hypothesis 5 (H5) that system state has a positive impact on the extent of cost system development. This result is also consistent with the empirical work by Shields (1995) and Eddy et al. (2003).

Organizational support ranked third $(\beta=1.829, \mathrm{p}=.005)$, these values support the hypothesis $4(\mathrm{H} 4)$ that organizational support has a positive impact on the extent of cost system development. It was argued in the literature that the development of cost system is relatively high in support from organizations. In this vein, Shields (1995); Eddy et al., (2003) argued that the choice of cost system is dependent on organizational support.

The factors that had the negative effect were X6 ( $\beta=-.3 .099, \mathrm{p}=.005), \mathrm{X} 7(\beta=-3.005, \mathrm{p}=.001)$ these values support the hypothesis 6 (H6) that satisfaction legal system has a negative impact on the extent of cost system development and the hypothesis $7(\mathrm{H} 7)$ that usage legal system has a negative impact on the extent of cost system development. The satisfaction legal system, usage legal system concepts and implications are consistent with the decreasing use cost system development (Innes \& Mitchell, 1995; Eddy et al., 2003). Thus, it can be expected that hospitals that pursue legal system are not likely to develop the cost system.

Based on this finding, the logistic regression equation is as follows:

$$
\log _{\mathrm{e}}\left[\frac{P(Y=1)}{P(Y=0)}\right]=36.577+7.886 * \mathrm{X} 1+1.829 * \mathrm{X} 4+2.581 * \mathrm{X} 5-3.099 \mathrm{X} 6-3.005 * \mathrm{X} 7
$$

where: $\quad \mathrm{Y}(\mathrm{Y}=1)=$ Use cost system according to state regulations with modified.

$$
\begin{aligned}
& \mathrm{X} 1=\text { Cost variability, } \\
& \mathrm{X} 4=\text { Organizational support, } \\
& \mathrm{X} 5=\text { System state, } \\
& \mathrm{X} 6=\text { Satisfaction legal system, } \\
& \mathrm{X} 7=\text { Use legal system. }
\end{aligned}
$$

\section{Conclusion}

The aim of this case study was to identify factors and explore the process influencing the implementation of cost system in Vietnam public hospitals. We have identified a number of factors which have influenced the implementation of cost system: cost variability, perceived complexity, organizational support, satisfaction legal system, use legal system.

The margin of error embedded in the traditional cost system was no longer tolerable in today's business environment. It is no longer sufficient for organizations to only provide service of high quality but organizations are also required to offer competitive pricing in order to survive in the marketplace. The stiff competition in this borderless world has forced many health-care organizations to press for more accurate information as basis for decisions. The traditional cost accounting system that relied heavily on averaging of overhead cost across various products could no longer satisfy this need. Thus, it is hoped that the pressure to compete be viewed positively by the market players. Public hospitals should strive to improve their competitiveness and one of the aspects is to improve their costing techniques to reflect this development.

The modern cost system long been seen as a tool to provide the management with a more accurate service costing. However, it should be noted that modern cost system provided the organizations with a whole spectrum of usefulness in decision making. The information generated from cost system can be used for planning, pricing, budgeting, and performance measurement. On the other hand, the decision to adopt new cost system required the public hospitals to invest financially by providing training, 
and software and hardware for the system. It also required investment in terms of man-hour and commitment from all levels. Therefore, organizations need to weigh the appropriateness of the system to the cost involved in adopting and implementing it. All the findings of this study describe the experiences of the participants regarding cost system development.

\section{References}

Abdullah, A., \& Senan, N. (2019). The complementary association between value chain analysis and target costing system to strengthen the competitiveness: An applied study on Saudi manufacturing companies in Al-Kharj. Management Science Letters, 9(10), 1543-1552.

Amiri, N., \& Khmidi, S. (2019). Implementing Time-Driven Activity-Based Costing (TDABC) in out-patient nursing department: A case from UAE. Management Science Letters, 9(3), 365-380.

Bjornenak, T. (1997). Diffusion and accounting: the case of $\mathrm{ABC}$ in Norway. Management Accounting Research, 8, 3-17.

Cooper, R., \& Kaplan, R. S. (1991). Profit priorities from activity-based costing. Harvard Business Review, 69(3), 130-135.

Cooper, R. (1988). The rise of Activity-based costing: when do I need an activity-based costing system. The Journal of Cost Management, Fall, 41-48.

Estrin, T., Ksntor, J., Albers, D. (1994). Is ABC suitable for your company? Management Accounting, April, 40-45.

Gapenski, L. C., \& Reiter, K. L. (2016). Health-care Finance: An Introduction to Accounting and Financial Management. $6^{\text {th }}$ ed., Chicago, IL: Health Administration Press.

Horngren, C. T., Foster, G., Datar, S. M., Rajan, M., Ittner, C., \& Baldwin, A. A. (2010). Cost accounting: A managerial emphasis. Issues in Accounting Education, 25(4), 789-790.

Ittner, C. D., Larcker, D. F., \& Meyer, M. W. (2003). Subjectivity and the weighting of performance measures: Evidence from a balanced scorecard. The Accounting Review, 78(3), 725-758.

Jackson, T. (2001). Using computerized patient-level costing data for setting DRG weights: the Victorian (Australia) cost weight studies. Health Policy, 56, 149-163.

Kaplan, R. S., \& Anderson, S. R. (2003). Time-driven activity-based costing. Available at SSRN 485443.

Kaplan, R. S., \& Anderson, S. R. (2007). The innovation of time-driven activity-based costing. Journal of Cost Management, 21(2), 5-15.

Kaplan, R. S., \& Cooper, R. (1998). Cost \& Effect: Using Integrated Cost Systems to Drive Profitability and Performance. Cambridge, MA: Harvard Business Press.

Kaplan, R. S., \& Porter, M. E. (2011). The big idea: How to solve the cost crisis in health care. Harvard Business Review, 89(9), 46-52.

Kerschner, M., \& Loper, E. (1987). Enhancing cost accounting efforts by improving existing information sources. Topics in Health Care Financing, 13(4), 10-19.

Krumwiede, K. (1998). The implementation stages of activity-based costing and the impact of contextual and organizational factors. Journal of Management Accounting Research, 10, 239-277.

Le, T., \& Nguyen, T. (2019). Practice environmental cost management accounting: The case of Vietnamese brick production companies. Management Science Letters, 9(1), 105-120.

McGowan, A. S. (1998). Perceived benefits of ABCM implementation. Accounting Horizons, 12(1), 31.

Paulus, A., Van Raak, A., \& Keijzer, F. (2002). Core articles: ABC: The pathway to comparison of the costs of integrated care. Public Money and Management, 22(3), 25-32.

Shields, M. (1995). An empirical Analysis of firms' implementation experiences with activity based costing. Journal of Management Accounting Research, 7, 148-167.

Velmurugan, M. S. (2010). The success and failure of activity-based costing systems. Journal of Performance Management, $23(2), 1-32$.

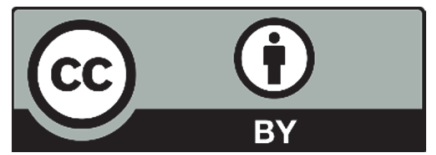

(C) 2020 by the authors; licensee Growing Science, Canada. This is an open access article distributed under the terms and conditions of the Creative Commons Attribution (CC-BY) license (http://creativecommons.org/licenses/by/4.0/). 